\title{
Moderate Step Over Sensitive Move Towards Mental Stress
}

\author{
P. Indhumathi, K.Rajeswari
}

ABSTRACT: Data classification study is applied in a profound manner to find some statistical classifier to analyze the higher order and lower order priors, like a hood to perform the posterior using Bayesian classifiers. The rough set approaches planned with functional and to determine the existence of the attribute with the level to correlation among them. Approximations towards the set of some logical factors were filtered towards to detect the mental stress through data collection mainly from the working people sector. Significant analyses to quantify the features of mental stress in various diseases cataloging manner with its technical aspects with its classification types based on the class value. As a proposed system of suggested hypothesis planned to predict the classifier model to reduce the stress dependency for the working people as much as possible in a smoother way.

Keywords: Bayesian classifiers, Data Exploration, Decision tress, Classification, Mental Stress, Rough set Approach

\section{INTRODUCTION}

Deep knowledge gathering towards mental stress and data mining are followed to flatten the exact witness to trace and cure them in future. The general survival based on the some sub topics covered related to mental as such like stress, illness, disorder, physical health issues, and retardation. Stress differs from one to another based on the capability of their understanding the situation. All aspects related to mental stress has some general cause, syndrome, treatment and risk factor. To diagnose the result some physical features has to be studied and undergone with some investigations terminology. While analyzing the cause of the stress, it generates based on their personal behaviors and mainly which depends on the surroundings of their life. Physically speaking the mental stress can be traced related to their behavior, physiology and psychological of the individual human. Some of the general cause of the stress is mostly related to level of composition exposed towards the problem facing in life. Behavioral situation which will be related to the major cause as money, work, environment climates, crime and soon.

Revised Manuscript Received on November 05, 2019.

* Correspondence Author

P. Indhumathi*, Research Scholar, Department of Computer Science, Tirppur Kumaran College for Women, Tirppur, Tamil Nadu, India

Dr.K.Rajeswari, Associate Professor, Department of Compute Science, Tirppur Kumaran College for Women, Tirppur, Tamil Nadu, India.

(C) The Authors. Published by Blue Eyes Intelligence Engineering and Sciences Publication (BEIESP). This is an open access article under the CC BY-NC-ND license (http://creativecommons.org/licenses/by-nc-nd/4.0/)

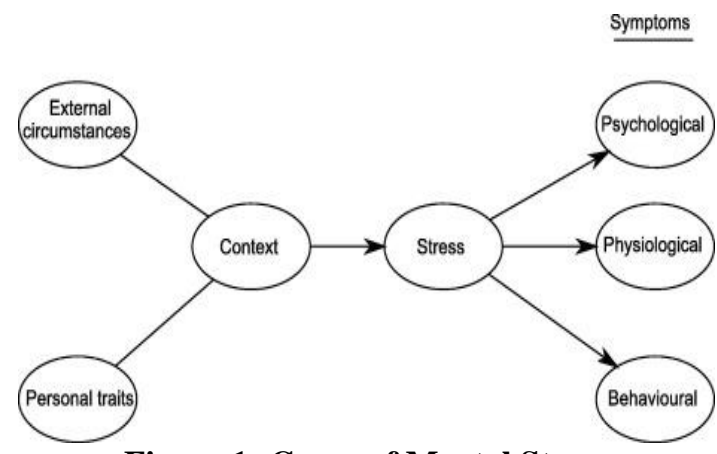

Figure 1: Cause of Mental Stress

Mental illness defines to prolong the behavioral condition which affects their mind personally based on the thinking, eating etc. It affects the health and regular activities, but it is common to all. Logically some sort of mood changes will be happen as like an emotionally, based on the thought's and behavior, almost all together will definitely depress our mind. Some of the indications of symptoms for Mental illness are:
$\checkmark \quad$ Feeling sorrowful always
$\checkmark$ Always in confused mind
$\checkmark$ Not concentrating properly
$\checkmark$ Curved changes on mood
$\checkmark$ Loss of energy
$\checkmark \quad$ Avoiding friends and family
$\checkmark$ Omitting the regular activities

Some of the mental syndromes are stomach pain, back pain or any other organ related pain. Most of the mental illness has to treat properly with the physician advice; otherwise it will be very risky to lead the human life.

\section{LITERATURE SURVEY}

[1] Research is related to adolescent trauma and exploring the effects and benefits for wellbeing in the region of Uganda. The whole research deals with the case study of the explanatory process. The technique applied in the work is specified as simple random and purposive sampling technique. The survey on the introduction part drafts with an analysis of the stress disorder attain over them mainly for children's in the age range from between 12 and 18 compared to adults. The cause of the attainment of the mental stress is address because of the poverty in their life (low income).The category of the work is survival with teachers, parents, social workers, students. The sample size is 86 and the total population is 110 and most of the stress is busted out through the focused features of group discussions.

Blue Eyes Intelligence Engineering

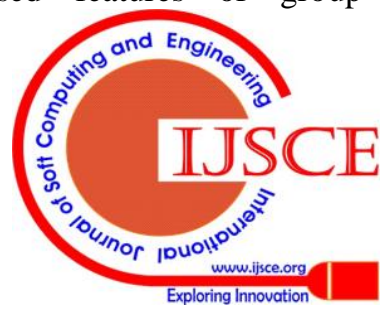




\section{Moderate Step Over Sensitive Move Towards Mental Stress}

The whole process data collection is techniques is applied through questionnaire method only. The actual reasoned causes of the stress studied over are:

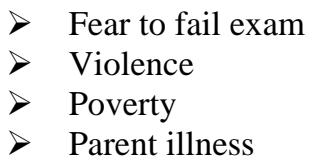
positive mental features with physical health is required. To conclude the study of the paper, counselor has to play the whole responsible features to integrate with the wellbeing with the required aspects by the focused group discussion over them through therapies. Mental state identifying manually may cause different critical issues, so their requires some medical testing to proceed further through signal of sensor data as an acquisition. The research methods are

$$
\begin{array}{ll}
> & \text { SVM (support vector machine) } \\
> & \text { Neural Network } \\
> & \text { Case-based reasoning }
\end{array}
$$

Case-based reasoning approaches are used based on two methods, they are

$$
>\text { Finger temperature }
$$

$>$ Heart rate variability

Compared to all the research methods, case-based reasoning provides good accuracy in the range of 80 to $86 \%$.

\section{RESEARCH OBJECTIVES}

The research objective is a riddle point to enhance the literal source and outcome of the process in a summarized way. The challenging workflow states to technologize the factor based on the dependency applicable towards the hypothesis. Expected outcome is the main motive or the objective of the research, this may appealed to be same or vary in accordance to the ratio defined in the research process. The main objective of the research works are stated to highlights stress handling factors mentally and physically. At some of the situation stress reveals based on the past history of the family and also with an another view is not sharing the issues to others or even to an supportive person, that may cause the change of emotional behavior, which lead to disorder like mood, anxiety and hyperactive disorder. In most of the case studies, stress leads to an mental disorder with the probability of anxiety disorder compared to others and soon. The expected outcome privileges to lead the exact impact factor of the mental stress with it resolving solution to make it as distress.

\section{IMPLEMENTATION ANALYSES}

The whole part of the research objective depends upon the question are:

$>$ Whether the working employers are affected by stress or not?

$>$ What type of stress is interface between them mentally?

$>$ How the inter-relevance between them is identified with the attribute parameters with the comparative tools?

In the detailed view of attribute selection method through the data collection method are stated and planned
To be wellbeing in the human life, good and

to handle them in nominal way, so all the factors related to numerical values are changed as per the required format in the dataset. The main reason for the interface cause to get a quick and clear decision towards the hypothesis. Interface approach are planned to integrate the source of action to reveal them in easy way and to distress from mentally and physically. Bursting out of stress can be depends upon the change in behavioral action towards the human, that can be with any type of disorder's like Anxiety disorder, Mood disorder, Eating disorder and Personality disorder. The research process is applied to find out the type of disorders highly affected towards the working employer's. Interrelevance are studied deeply towards the mining process in two ways technically as,

$>$ Firstly, Data sets divides into two groups and provide two class values, by cross -sectional analyses at certain time

$>$ Secondly, compare the result sets and simulate in two different tools with different technique.

The working hypothesis are planned with many expected outcomes with the correlational features on the attributes, roughly drafting the disorder dependency is between anxiety and mood, which will be highly affected and many depends on the surroundings and the work pressure for them with the primary role play in the organization.

\section{ATTRIBUTES DEFINITION}

Tabl1 1: Attribute definition

\begin{tabular}{|l|l|l|}
\hline $\begin{array}{l}\text { s.n } \\
0\end{array}$ & $\begin{array}{l}\text { ATTRIBUTE } \\
\text { NAME }\end{array}$ & DESCRIPTION \\
\hline 1 & Self employed & to state about the self- employee \\
\hline 2 & Employees count & $\begin{array}{l}\text { total number of employee in the } \\
\text { organization }\end{array}$ \\
\hline 3 & Tech company & is it an IT company or not \\
\hline 4 & Primary role & did your role is very important \\
\hline 5 & Shareff & did you share your stress with friends \\
and families
\end{tabular}

Published By:

Blue Eyes Intelligence Engineering 


\begin{tabular}{|l|l|l|}
\hline 12 & If so & what type of stress did he suggests \\
\hline 13 & Treatment & status of the treatment undergone \\
\hline 14 & Affects work & $\begin{array}{l}\text { is the stress affected the work after } \\
\text { treatment }\end{array}$ \\
\hline 15 & Not affected & $\begin{array}{l}\text { is the stress affected the work without } \\
\text { treatment }\end{array}$ \\
\hline 16 & Age & age of the employer \\
\hline 17 & Gender & gender of the employer \\
\hline 18 & Work remotely & do you work remotely? \\
\hline
\end{tabular}

\section{RESULTS AND DISCUSSION DECISION TRESS APPROACH :}

The research process starts to evaluate the methods based on the parameter dependency with its priority. The rough set approach is the beginning methods which detect the order and the dependency among them in first level and second level class value with its attribute selection methods.

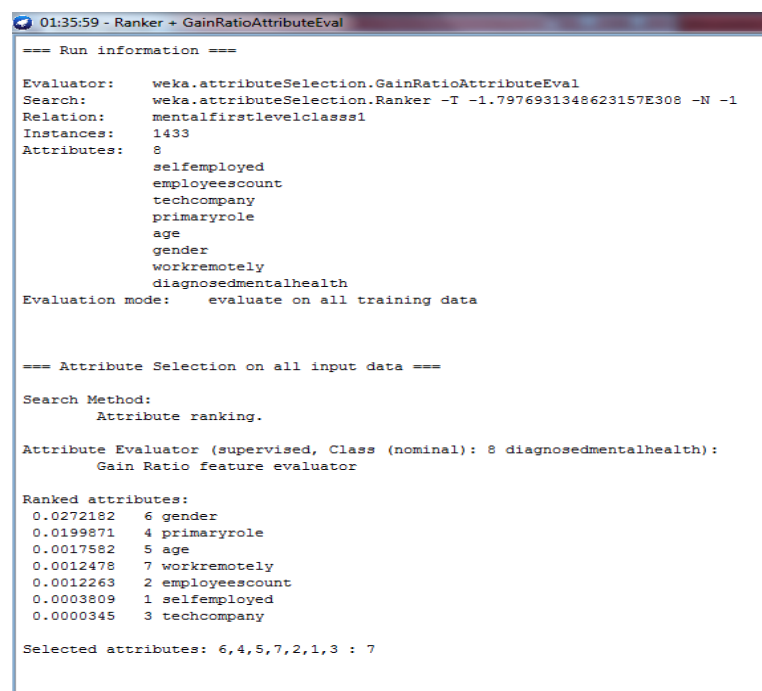

Figure 2.Attribute selection for first level class value

The attribute ranking is applied to valuate the research process to integrate the rough-set approach to identify the attribute parameters to detect the status of the mental health of the employer. The parameters utilized are used to analyse the first level of mental stress the attribute purpose are:

1.Self employed - either the employer works in private or public concern, it is represented as yes or no ,whereas yes presented private and no represent as public concern

2. tech company- either it is an IT company or not, yes resembles it is an IT company where as no resembles other companies

3.primary role : it is used to identified the job level with their roles and responsibility as important or not
4. employee count: total number of employees in the concern (co-workers), if the company holds with

$\checkmark$ Minimum below 100 -low (beginner level company)

$\checkmark$ Between 100-500 -medium (company running more than 5 years)

$\checkmark$ Greater than $500 \quad$ - high (govt sector)

5. age - to catalog them as soon as with the age as well as with their primary role
$\checkmark \quad$ Freshers - between to 21 and 35
$\checkmark$ Experienced - between 36 and 45
$\checkmark \quad$ Senior - above 46

6. gender : to identify the gender as either male or female 7. work remotely: to identify the role to access the system remotely are not

$\checkmark$ Never - job role may be designer, document checker and soon

$\checkmark$ Sometimes -job role may be backend support , business analyst, web analyst

$\checkmark$ Always - system , network, database ,manager,admin and soon

8. diagnose mental health - from the first set of parameters to identify the class values as Yes or no

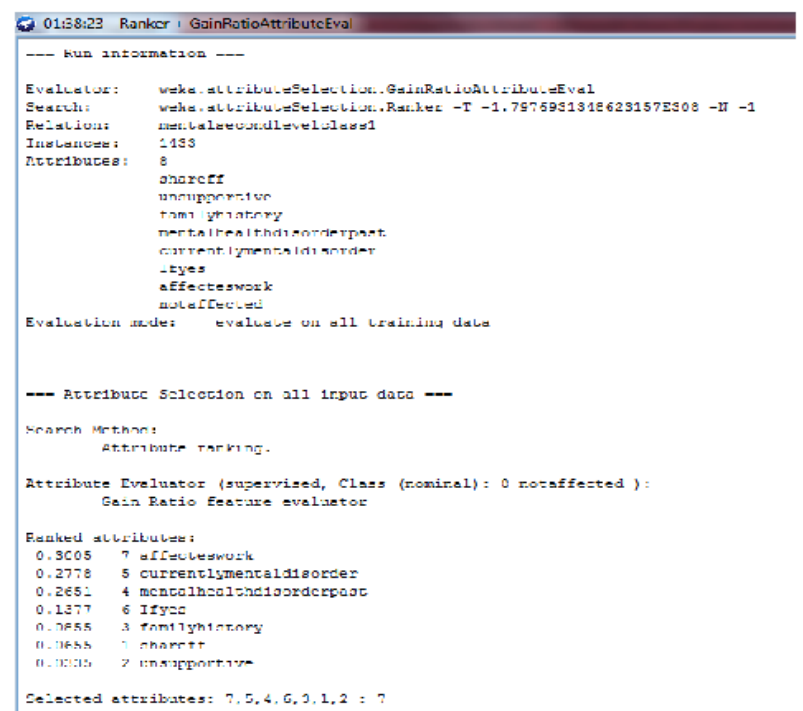

Figure 3: Attribute selection for first level class value

The purpose of applying the attributes in the second level class value dependence are:

1.shareff - To check whether they share with friends and family about their mental stress, it is represented as yes or no

2. unsupportive - did they have any supportive person or not? Attribute values are denoted as yes or no

3. family history- did they have any family history regarding the mental illness and about mental stress

4.mentalhealthdisorderpast- did the employer had any past history about mental health

5.currentlymentaldisorder - did the employer had any mental disorder right now.

6.ifyes- what type of mental disorder is identified like

$\checkmark$ Anxiety disorder

$\checkmark$ Mood disorder

Blue Eyes Intelligence Engineering

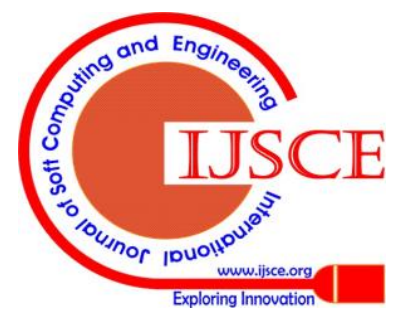


Moderate Step Over Sensitive Move Towards Mental Stress

$\checkmark \quad$ Anxiety and mood disorder

$\checkmark$ Eating disorder

$\checkmark$ Personality disorder

$\checkmark$ Hyperactive disorder

$\checkmark \quad$ Eating and personality disorder

7.affecteswork- either the mental disorder affects the work or not.

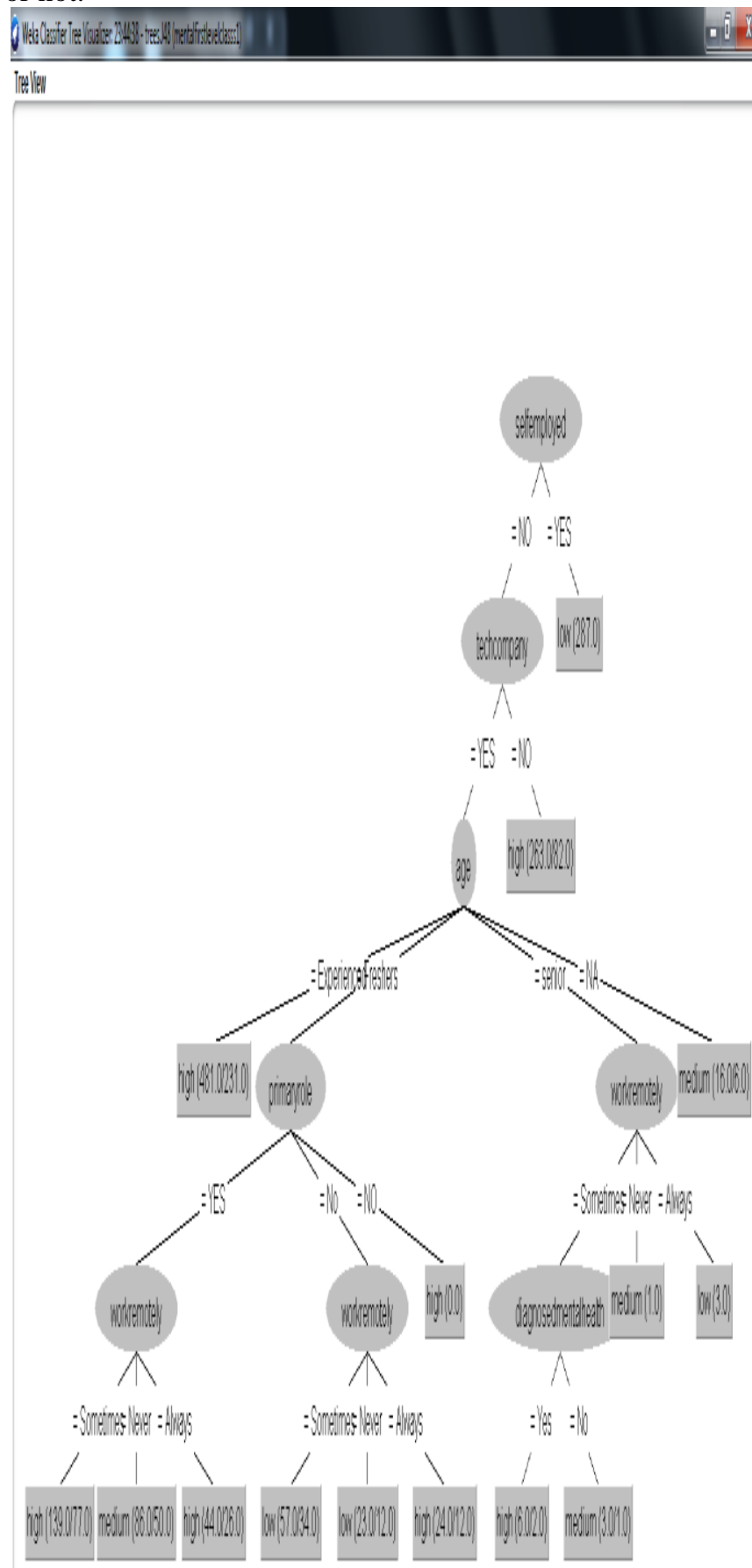

Figure 4: tree view analyser

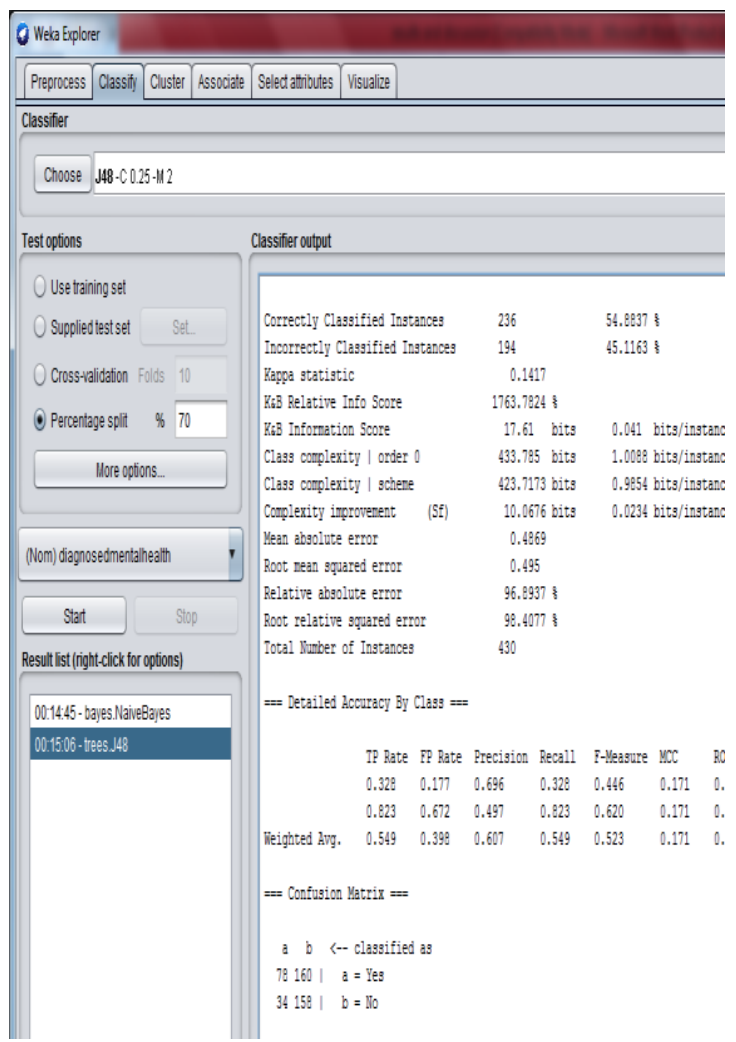

Figure 5 : j48 approach

Navies bayesian Approach :

Bayesian approach is main used to evaluate the data based on the statistical as well as probability values to interrogate the like-hood and posterior for the real time dependencies . the navies approach is applied by choosing the classifier with the percentage of test set spiting along with attribute specification.

J48 decision trees provides an accurate result over the parameter age, gender , self employed, and diagnose the mental disorder compared to navies tool in weka. The second level of class parameters are defined to evaluate the confusion matrix to prolong the survival in high defined approach in some ways are:

$\checkmark$ Diagnosing the Mental stress, which affects the work in naviyes view

$\checkmark \quad$ Navies approach in if yes attributes

$\checkmark$ approach based on mental history on past

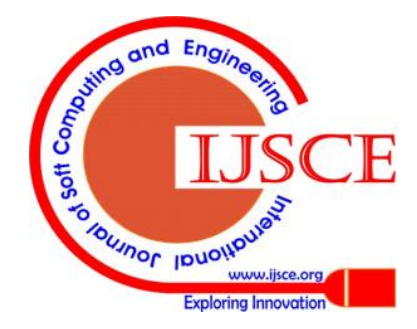




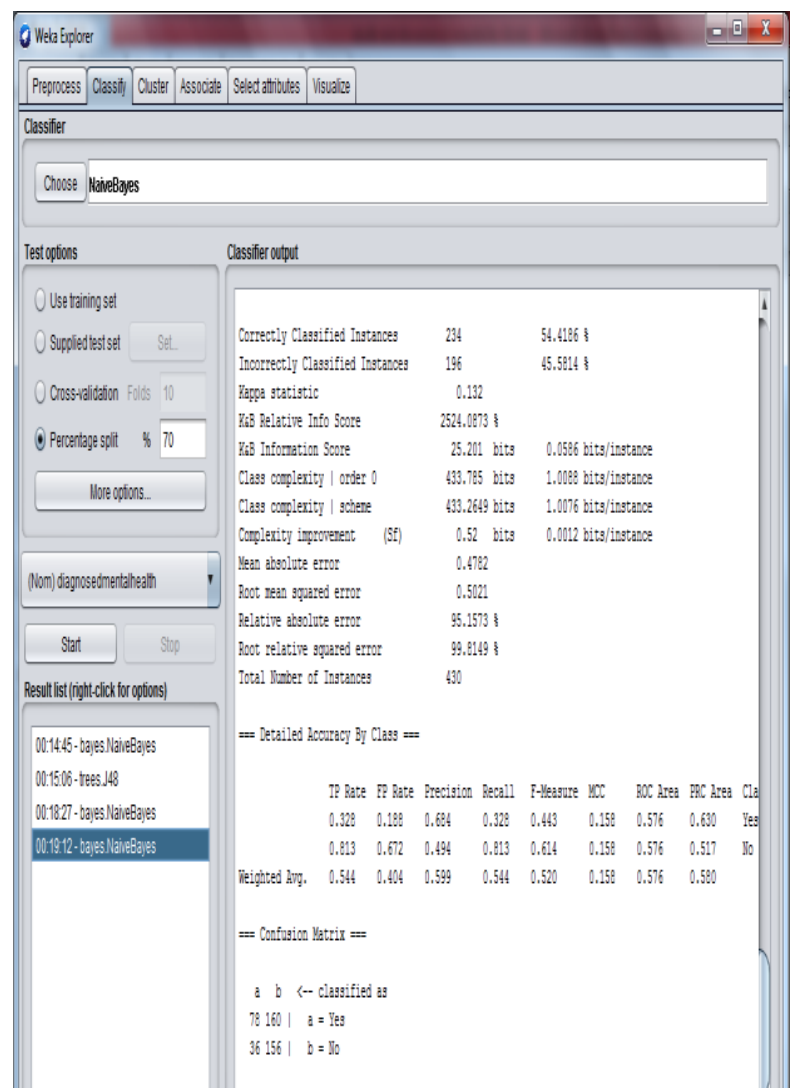

Figure 6: :navies approach

\section{CONCLUSION}

In the first level of predication of data, there may be chance for mental illness is diagnosed, but requires some more medical relevant data also. Fresher's are more stressed compare to experienced person in the technical sector. Similarly whoever often remotely working employers are more stressed. In the second level of predication of data, mental illness are changed to mental disorder because of not sharing their issues with others and also having some past mental history. Almost the mental disorder are highly results to anxiety and mood disorder, which reveals to be panic always on their mind with full of depression. It could be manageable to perform well as an employer to an organization, if the person is mentally has the capacity to control the emotional behaviors more than the physical features.

\section{REFERENCES}

1. Ankwasiize Evarist, "_Adolescent Trauma and Psychosocial Wellbeing in Entebbe-Uganda", Universal Journal of Psychology 6(3): 67-79, 2018 , DOI: 10.13189/ujp.2018.060301

2. Radhika Deshmukh,"_Mental stress level classification: A Review", International Journal of Computer Applications (0975 - 8887)

3. Shaibal BARUA, Shahina BEGUM and Mobyen Uddin AHMED," Supervised Machine Learning Algorithms to Diagnose Stress for Vehicle Drivers Based on Physiological Sensor Signals"

4. C. Goumopoulos , E. Menti ", Stress Detection in Seniors Using Biosensors and Psychometric Tests", International Conference on Pervasive Computing Advances and Applications - PerCAA 2019

5. Dr. Deepti Bhargava,,Hemant Trivedi,"_A Study of Causes of Stress and Stress Management among Youth”,_IRA-International Journal of Management \& Social Sciences,_ISSN 2455-2267; Vol.11, Issue 03 (June 2018),Pg. no. 108-117.
6. D.Umanandhini, SURVEY ON STRESS TYPES USING DATA MINING ALGORITHMS",_International Journal of Innovative Research in Advanced Engineering (IJIRAE), ISSN: 2349-2163, Issue 04, Volume 4 (April 2017) www.ijirae.com

7. Sumathi, Dr.B.Poorna, "Prediction of Mental Health Problems Among

Children Using Machine Learning Techniques",__(IJACSA) International Journal of Advanced Computer Science and Applications

8. https://www.mayoclinic.org/diseases-conditions/mentalillness/symptoms-causes/syc-20374968

9. https://www.helpguide.org/articles/stress/stress-symptoms-signs-andcauses.html

10. https://www.who.int/news-room/fact-sheets/detail/mental-disorders

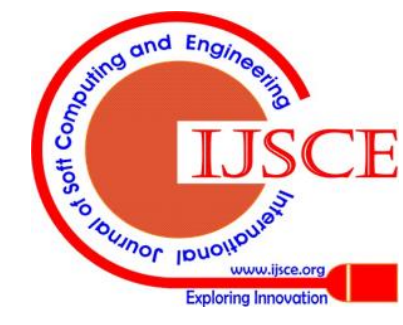

